\title{
Article \\ Perceptions about the Future of Integrating Emerging Technologies into Higher Education-The Case of Robotics with Artificial Intelligence
}

\author{
Janika Leoste ${ }^{1, * \mathbb{D}}$, Larissa Jõgi ${ }^{1}$, Tiia Õun ${ }^{1}$, Luis Pastor ${ }^{2}$, José San Martín López ${ }^{2}$ and Indrek Grauberg ${ }^{3}$ \\ 1 School of Educational Sciences, Tallinn University, 10120 Tallinn, Estonia; larj@tlu.ee (L.J.); \\ tiiaoun@tlu.ee (T.Õ.) \\ 2 School of Computer Science \& Engineering, Universidad Rey Juan Carlos, Calle Tulipán, s/n, Móstoles, \\ 28933 Madrid, Spain; luis.pastor@urjc.es (L.P.); jose.sanmartin@urjc.es (J.S.M.L.) \\ 3 School of Governance, Law and Society, Tallinn University, 10120 Tallinn, Estonia; indrek.grauberg@tlu.ee \\ * Correspondence: leoste@tlu.ee; Tel.: +372-504-5081
}

\section{check for} updates

Citation: Leoste, J.; Jõgi, L.; Õun, T.; Pastor, L.; San Martín López, J.; Grauberg, I. Perceptions about the Future of Integrating Emerging Technologies into Higher Education-The Case of Robotics with Artificial Intelligence. Computers 2021, 10, 110. https://doi.org/ $10.3390 /$ computers10090110

Academic Editors: Ioana Andreea Stefan and Samir Garbaya

Received: 30 July 2021

Accepted: 6 September 2021

Published: 8 September 2021

Publisher's Note: MDPI stays neutral with regard to jurisdictional claims in published maps and institutional affiliations.

Copyright: (c) 2021 by the authors. Licensee MDPI, Basel, Switzerland. This article is an open access article distributed under the terms and conditions of the Creative Commons Attribution (CC BY) license (https:// creativecommons.org/licenses/by/ $4.0 /)$.

\begin{abstract}
Emerging technologies (ETs) will most likely have a strong impact on education (starting with higher education), just like they have already had in so many economic and social areas. This paper is based on the results obtained in the project "My Future Colleague Robot", an initiative that aimed to improve the competence of university teaching staff regarding the introduction of ETs in teaching practices at university level. In this paper, we identified the strengths and weaknesses, opportunities, and threats that are related to the adoption in higher education of the combination of two ETs: robotics together with artificial intelligence (AI). Additionally, we analyzed the perceptions of university-level teaching staff about the potential of introducing ETs in education. The empirical data presented here were collected using written essays from 18 university teachers and students. Deductive and inductive approaches with thematic analysis were used for the data analysis. The findings support the idea that previous ET-related experience can support positive attitudes and the implementations of ETs in university teaching; in this study, university teachers had optimistic expectations towards ETs, accepting them as part of teaching practice development, while discussion about the negative effects of ETs was negligible.
\end{abstract}

Keywords: emerging technologies; educational innovation; artificial intelligence; robotics; higher education; teaching practices

\section{Introduction}

This paper is based on the results of the one-year international development project "My Future Colleague Robot", a project conceived for raising and developing the competence of Tallin University (TU) teaching staff regarding the integration of some emerging technologies (ETs) into different higher education disciplines. Specifically, two ETs were selected: artificial intelligence (AI) and robotics, through the consideration of complex, AI-enhanced educational robots. The selection of the combination of AI and robotics for the TU study came as a logical consequence of the increased diffusion of robots in many education stages in Estonia, starting at kindergarten level.

In general, the concept of "ETs" includes both novel technologies and existing technologies that, combined with new niche contexts, have the potential of becoming mainstream tools in these new niches [1]. According to Rotolo, Hicks, and Martin [2], an emergent technology is characterized by five key attributes: (a) radical novelty; (b) relatively fast growth; (c) coherence; (d) prominent impact; and (e) uncertainty and ambiguity. Adner and Levinthal [1] also point out that ETs are often generated by the Schumpeterian combination of an existing technology with a new context; thus also fitting Schumpeter's [3] definition of technological innovation. As such, it is reasonable to assume that emerging technologies 
follow the innovation adoption processes, as described by Rogers [4], Davis [5], and others. In time, ETs either become a part of the end-users' daily routines and lose their novel nature (see [6]) or fail in this process (see [7]).

Often, the status of novelty of ETs is based not only on their originality, but also on the possibilities of initiating new ways and approaches for doing something-for example, coordinating pedagogical activities, social interaction, and knowledge construction in the educational process [8]. However, due to their innovative nature, ETs are mostly untested in real-life situations, and their link to pedagogical approaches and activities in higher education is often insufficiently developed. As researchers, we were interested in how university teachers and their students envision the changes that ETs could cause in society in general, and particularly in their disciplines. As commented before, the cases of AI and robotics were selected because of their relevance and presence in educational environments.

From a historic perspective, major technological changes have led society almost always towards making ever-increasing demands on education [9], with the latter trying to catch up the status quo of the social needs, newly created by ETs. Emerging technologies bring novel and fast-growing approaches that will have a potentially strong future impact on actors, institutions and their interaction patterns within socio-economic domains, along with the associated knowledge production processes [2]. Scientific knowledge creates new opportunities and solutions that can enrich our lives, while, at the same time, fueling disruptive waves of change in every sector. Unprecedented innovation in science and technology, especially in biotechnology and artificial intelligence, is raising fundamental questions about what it is to be human [10]. For these reasons, ETs typically have a broad impact on the people's everyday routines, allowing them to reshape their own relationship with the world and their perception of reality [11]. In the 21st century, ETs are used more with jobs of a non-repetitive nature, consisting of tasks that require thinking and, in general, require intellectual creativity [12]. In education, some ETs are considered crucial $[8,13,14]$ :

- Artificial Intelligence, which can facilitate some tasks, provide students with adaptive learning environments, differentiated learning tools and feedback, even perhaps allowing to completely replace human teachers in some specific cases. Together with Big Data, AI lays grounds for evidence-based education [15].

- $\quad$ Big Data (BD), which involves large and complex datasets that are not easily managed by traditional methods [16]. BD facilitates various forms of analytics in education, such as learning analytics (a tool for monitoring student learning progress and for providing individualized guidance), wellbeing analytics (a promising tool for combating mental health related challenges), and curriculum analytics (a tool for analyzing which curriculum parts work well and which need improvement).

- Immersive and advanced visualization technologies, including virtual reality (VR) and augmented reality (AR) tools, which allow the cost-effective creation of specialized learning environments for either STEM learning and in developing 21st century skills in higher education [17], help to improve student learning performance and outcomes [18], even within open-ended social and collaborative interactions and intentional, personalized learning, which makes e-learning more meaningful [19].

- Robots, which can be used as: (a) learning tools for robotics (for teaching either robotbuilding and coding or using robots in different application areas such as medicine, manufacturing, etc.); (b) engaging learning tools for developing 21st century skills and enhancing teaching of other disciplines such as maths and physics [20,21]; and (c) as peers and tutors when combined with artificial intelligence.

- Simulations, virtual labs, gaming, and technology-mediated play can be used to make science more accessible in the K-12 classroom context, as these technologies allow presenting real-life phenomena (such as chemical reactions, climate change or math constructs) to students in easily observable and more engaging ways.

- Computational thinking (CT), which is a mental tool for handling complex situations that involve thinking, such as managing data, problem solving, or understanding 
complex systems. CT goes far beyond computer programming and does not need to involve computers at all [8].

These ETs open a variety of new opportunities in education. On the one hand, institutions can improve their administrative efficiency [14], cutting various costs in the process. Furthermore, as learners will have more freedom to determine their own pace and location of learning, these technologies can support self-determined learning [22] and contribute to the shift from an instructor-led education to a learner-based educational environment [23]. On the other hand, these changes challenge the established ways of teaching. The ability of ETs to support curricula upgrades is an opportunity and obligation for the educational institutions in order to develop appropriate pedagogical approaches that support adopting new ways and policies for teaching and learning [23]. Even in the cases when educational institutions have already implemented some 21st century skills to their curricula, there is a need for developing systematic approaches, supported by appropriate pedagogies and assessment procedures [23]. This process is often obstructed by teachers' hesitance that has various origins [24]. In higher education, it is necessary to evolve new technological developments and use them effectively to facilitate learning [25].

\subsection{Robotics with Artificial Intelligence}

In this paper, we focus on ETs in the higher education context. In particular, we observe the combination of two ETs, AI, and robotics. Some comments about the reasons behind this choice were already stated above. Additionally, some other reasons can be added, derived from the fact that robots are machines, designed to autonomously perform specific tasks. The purpose of a robot determines its appearance, intelligence, and other characteristics. Robots are usually categorized by the following attributes [26]: (a) their operating environment-marine robots, space robots, etc.; (b) their interaction with users-autonomous, programmed, tele-operated, or collaborative robots; (c) their physical characteristics - nano robots, exoskeletons, robotic arms, etc.; and (d) their primary purpose-self-driving cars, assembly line robots, robotic lawn mowers, etc.

Due to technological advances and improvements in computing power accessibility, an increasing number of robots (in the widest sense of the term) are being driven by AI methods, allowing robots to be used in areas where human intelligence is usually required [27] - for example, holding a conversation with people or making financial investments [28]. AI is considered to be weak when the robot merely imitates human behavior, or strong if the robot is able to learn from its previous experiences [29]. AI-enhanced robots are seen as promising in many areas, from healthcare to manufacturing, due to them being precise and flexible, allowing reducing costs while saving energy and other resources [30]. Due to the existence of android robots, robotics in general can often be perceived as a threat to people's jobs and way of life, as it is easier for a person to envision human-like robots with superhuman abilities to make the actual humans obsolete in the workplace and even in their private lives. However, some studies confirm that such hostile attitudes towards robots are subject to fade if people have a personal experience with robots [31,32].

In the recent decades, there have been significant advances in both robotics and AI fields, resulting in the development of new robots and applications. It is relevant to mention the emergence of anthropomorphic or zoomorphic robots that employ AI for their movement and behavior, such as the Boston Dynamics' Atlas robot, with its ability to parkour and carry out other complex human movements [33]. Furthermore, the combination of android robots with advanced AI can result in machines that may be perceived as human-like creatures, having the potential to intervene in, perhaps, all domains of human life. Proliferation of such machines could cause surfacing of new communication patterns that are more efficient in connecting people with AI-enhanced robots. However, it could also cause people to reuse their existing communication patterns with robots, extending the ways of how we perceive and deal with machines. This, in turn, could even lead to extending some legal and moral rights that have been until now reserved for people to both people and robots—with results that cannot be clearly predicted 
as of today. We assumed that it is relatively easy for the people without previous training to theorize about the various impacts of AI-enhanced robots on their private and working lives, as well as on society.

\subsection{Research Questions}

Due to their revolutionary impact, ETs tend to require fundamental changes in existing processes in order for the positive effects to be highlighted [34]. This characteristic can be problematic in education, as teachers are reported to start changing their teaching methods only after they have already acquired the necessary skills and knowledge to work with the new technologies [35]. In addition, teachers as knowledge workers tend to resist instructions and models from outside of their communities, viewing formal processes as annoying [36], instead of leaning on their personal perception about the usefulness of the ETs in their teaching practices. Convincing teachers to accept and adopt novel technologies may require good understanding about the teachers' perspectives [37], as they are well familiar with the matters of pedagogy, teaching, and learning, just like students are familiar with their indirect learning needs. Bringing a novel technology with its accompanying methods into existing teaching practices at the universities requires introduction of the technology to the teachers, gathering their feedback, and constructing an implementation plan that considers the needs of teachers. The current study was conducted at an Estonian university. While Estonian students have been internationally known for their good PISA results [38], it is also criticized that learning in Estonian educational institutions is not sufficiently learner-centered and current professional education in higher education does not sufficiently support the development of students' future skills [39].

Using the example of AI-enhanced robotics, the aim of this paper is to gain a deeper understanding about the university teachers' perceptions on AI-enhanced robotics, on ETs in general in their future lives, on their impact on the society in general, and on the influence on their disciplines and teaching practices in particular. This aims to contribute a point of departure for programs that aim to integrate ETs into higher education. Using AI-enhanced robotics as an example of ETs, we have formed the following research questions:

1. What are the strengths, weaknesses, opportunities, and threats of proliferation of AI-enhanced robots, from the point of view of university teachers and students?

2. What are the perceptions of university teachers related to emerging technologies in general?

Next, we continue our paper by providing background information about the project "My Future Colleague Robot" and then presenting the methodological framework of the research. To answer our research questions, we present empirical results and discuss the analytical findings from the deductive and inductive analysis. Finally, we present a collective story, which draws attention to the voices of university teachers, and conclude the paper with some suggestions for future research.

\section{Materials and Methods}

The project My Future Colleague Robot was conducted at Tallinn University from July 2020 to June 2021. One of the results of the project was the elaboration of the Vision Book, which focused on the roles of ETs, especially on those of robotics and AI, in education and everyday life. The participants of the project (university teachers and their students) were asked to contribute to writing this book, stating their thoughts and assumptions, related to using AI-enhanced robots in higher education, using a freewriting approach [40]. For this, they had to write an essay or record a video about their vision on how ETs are going to be used in education and everyday lives in the future. The participants were given three months (from February 2021 to June 2021) to independently write and complete their submissions. Each contribution became a separate chapter in Vision Book.

The participating teachers and their students were teaching and learning at the university in different disciplines, had different academic positions, and had agreed with the invitation to participate. The purposeful sample group was formed, consisting of 18 higher 
education teachers and students from different disciplines and generations. A final sample group $(\mathrm{N}=18)$ consisted of 7 women and 11 men; 8 were from STEM disciplines, and 10 from the humanitarian and social disciplines. Based on the academic positions, the participants were professors (2), associate professors (4), lecturers (6), researchers (3), bachelor students (2), and a master's student (1). None of the participants from the humanitarian and social disciplines had integrated ETs to their teaching practices before or during the development project.

Empirical data were collected from the Vision Book chapters according to agreements made between the researchers and the members of the sample group. Written essays and transcriptions of recorded videos were coded using numbers in the same order as they were structured in the Vision Book. Data analysis was based on the interpretive paradigm [41]. For empirical analysis, we used a combination of two approaches: "top down" — a deductive approach for the first research question, and "bottom up" —an inductive approach for the second research question [42]. Deductive and inductive approaches are appropriate for our research because we analyze the qualitative data [37]. A deductive approach for empirical data analysis was used in order to explore causality between meanings (Research Question 1) and an inductive approach-in order to inductively analyze the meanings and explore phenomenon (Research Question 2).

We used the inductive approach with thematic analysis [42], focusing on the common themes, also on variations of meanings in the empirical data. As researchers, we were interested in how the participant described and understood a complex future phenomenon [43], related to ETs. Finally, based on findings from the thematic analyses, we constructed a collective future story [44] and presented it in the final part of our paper.

In the analyzing process, the following steps and procedures were used. First, the videos were transcribed and the empirical material together with data from essays were anonymized and coded using numbers (for instance, T1, T2, etc.). Research Question 1 was formed based on the principles of the SWOT approach (a tool that is used to improve decision-making when planning complex future strategies) [45]. In accordance with the aim of the research project, the SWOT method was used as an interactional analytical tool for collecting empirical data related to internal (strengths and weakness) and external (opportunities and threats) factors [46]. Based on Research Question 1, a deductive approach using selective coding was used. Using a deductive approach in the process of data analysis means that coding has included structuring the data based on the four general categories of SWOT methods: strengths, weaknesses, opportunities, and threats. This then created new subcategories, which appeared from the empirical material. The subcategories were held on a level as abstract as possible in order to avoid several codes with a similar meaning that are difficult to encapsulate. Each subcategory was counted only once per text, if present. If the following text gave rise to a similar subcategory then before creating a new one, it was considered whether rephrasing an existing one would be a better option. The created subcategories and their occurrences were entered into a data table (Table 1), creating a basis for the subsequent processing.

The coding and data analysis was conducted by two researchers. The agreement about codes was created via thorough discussions before, during, and after the coding process, with the purpose of relaying the true representation of the meaning of the texts. 
Table 1. Categories of meanings and subcategories.

\begin{tabular}{|c|c|c|}
\hline $\begin{array}{c}\text { Main } \\
\text { Categories }\end{array}$ & Subcategories & Occurrences \\
\hline \multirow[t]{8}{*}{ Strengths } & Support people in their work & 17 \\
\hline & Support people in their private lives & 14 \\
\hline & Support learning & 12 \\
\hline & Are convenient to use & 7 \\
\hline & Are irreplaceable in some areas & 6 \\
\hline & Entertain people & 4 \\
\hline & Support students with special educational needs & 3 \\
\hline & Are cost-effective & 2 \\
\hline \multirow[t]{9}{*}{ Weaknesses } & People need training programs about ETs & 9 \\
\hline & People lack sufficient understanding about ETs & 8 \\
\hline & Are initially confusing & 5 \\
\hline & People are biased towards ETs & 4 \\
\hline & ETs are difficult for the general public & 2 \\
\hline & ETs can be costly & 2 \\
\hline & Legal aspects & 2 \\
\hline & ETs are difficult to integrate to education & 1 \\
\hline & Reliability problems & 1 \\
\hline \multirow[t]{9}{*}{ Opportunities } & Free people for other things, change in roles & 8 \\
\hline & Enhance people's abilities & 6 \\
\hline & Make new things possible & 5 \\
\hline & Allow social advances in community & 5 \\
\hline & Support transformation of teaching practices & 5 \\
\hline & Support kids with autistic or similar disorders & 2 \\
\hline & Save resources & 2 \\
\hline & Can increase equality and equity in education & 1 \\
\hline & Create new jobs & 1 \\
\hline \multirow[t]{5}{*}{ Threats } & Change labor roles and needs & 9 \\
\hline & Threaten social and emotional aspects (human way of life) & 8 \\
\hline & Replace humans & 7 \\
\hline & Can lead to wasting resources & 1 \\
\hline & Convert humans to robots & 1 \\
\hline
\end{tabular}

For the second research question, an inductive approach using thematic analysis was used. The inductive analysis process was based on six steps, and was carried out in order to understand the university teachers' perceptions of issues related to ETs. The following steps were used in this process: reading empirical material and searching for meanings; generating initial codes; searching for themes; reviewing and refining themes; defining common themes [42]; and finally, narrative coding of common themes. This last step was used for constructing the collective story [47] (p. 109), [48], using elements of inductive analysis and conceptual memos from two researchers. The collective story presented research data in the form of a dialogue between participants [44], and could be used to create immersive scenarios of the future that engage us as a scholar on an emotional and intellectual level [49]. To ensure the trustworthiness of data analysis and that the themes from analysis reflected the participants' voices, we used peer debriefing and returned several times to the raw data [50].

The next section of our paper presents the main results of our empirical analysis, based on the research questions stated in Section 1.2.

\section{Results}

3.1. Strengths and Weaknesses, Opportunities and Threats of Implementing Emerging Technologies to Teaching Practices and Learning Process

Our first research question was: "What are the strengths, weaknesses, opportunities, and threats of proliferation of AI-enhanced robots, from the point of view of university 
teachers and students?" To answer this question, we first observed which of the four major categories of meaning were most represented in participants' contributions, by counting the occurrence of different subcategories (Figure 1) in the empirical material. Each subcategory was counted once.

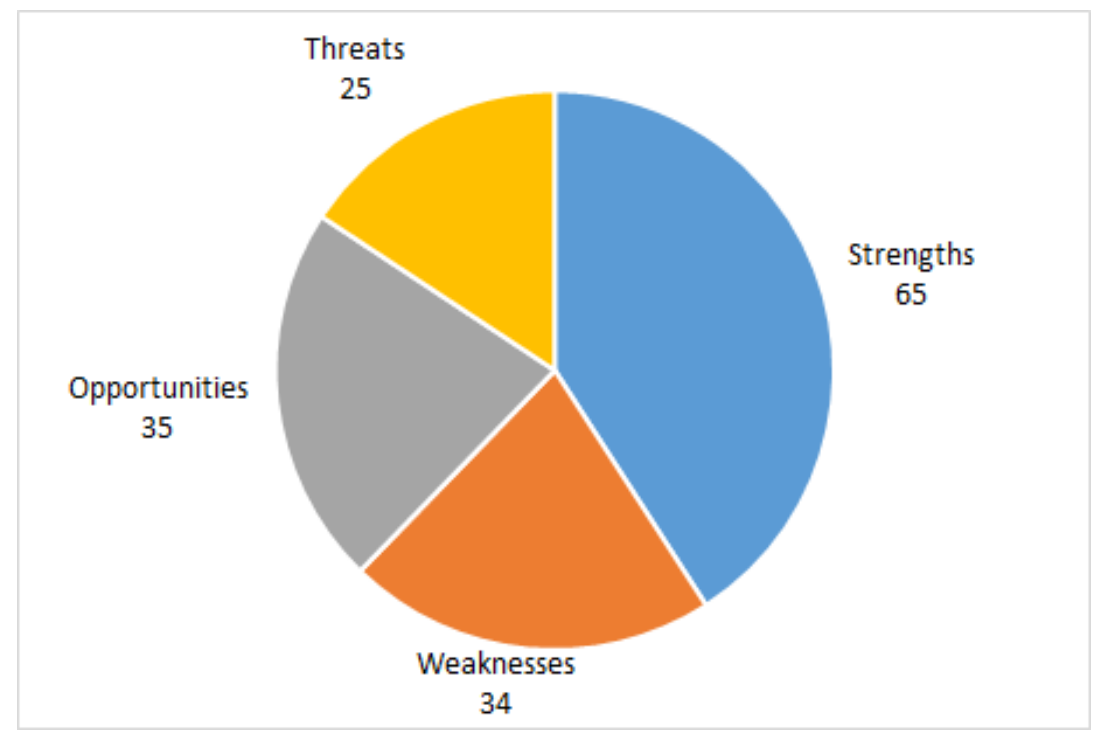

Figure 1. Number of subcategory occurrences in participant's contributions.

We found that the participants were optimistic about robotics and AI; they mostly highlighted the strengths (65 occurrences in 8 subcategories) and opportunities (35 occurrences in 9 subcategories) of these technologies. For example (strengths, T2): "they are accepted and will be accepted because they are or will be convenient," or (opportunities, T5): "The next step from here is an anthropomorphic-looking home aid who does all the house chores, up to indeed a romantic object of love, that is a robot who would be able and perform nearly all or all functions of a human companion in a romantic relationship. And here we cannot draw the line that it would perform the same functions as a human would, it could do so much more." The participants also discussed the weaknesses of robotics and AI (34 occurrences in 9 subcategories), for example (T9): "It is true that when we have no previous experience, knowledge and imagination - then sometimes we lean on our biases, we will not develop new connections and meanings, we don't think about it, we avoid or ignore the need for something new." The threats associated with ETs were identified less frequently (25 occurrences in 5 subcategories), for example (T3): "On the other hand, using robots may lead to excess or waste, that is if they are implemented in places where it is not perhaps needed."

Secondly, we examined how many different subcategories in each major category of meaning (Figure 2) were identified by at least a quarter of the participants, allowing us to highlight the repeating patterns, and see how coherent the knowledge about a particular category across the participants was. The participants were more knowledgeable about the positive aspects of reviewed technologies. Both in the strengths and opportunities codes, five subcategories were present in at least $25 \%$ of the participants' contributions, compared to three subcategories in weaknesses and threats. 


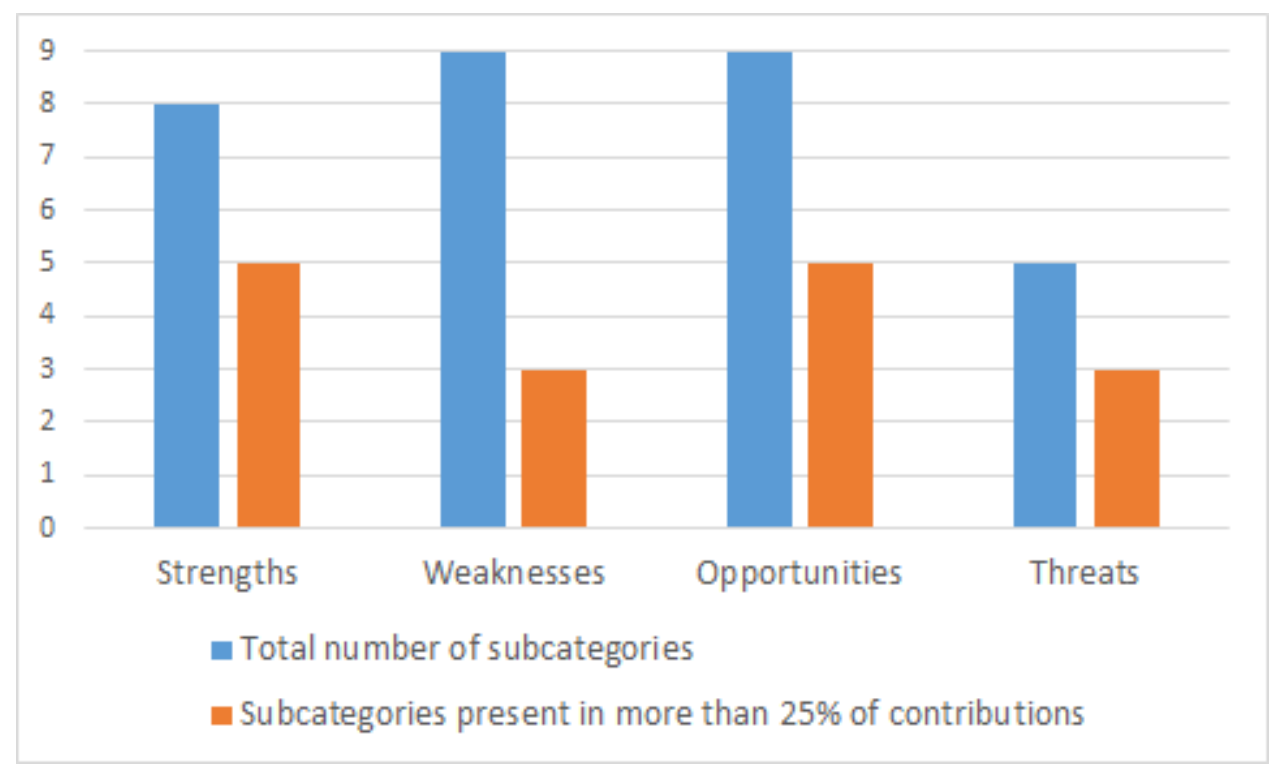

Figure 2. Number of subcategories in each major category.

The most used subcategories revealed certain areas of interest for the participants. In the strengths category the subcategories, "Support learning", "Support people in their work", and "Support people in their private lives" indicate that sophisticated robots and $\mathrm{AI}$ are in the first place seen as tools that support people everywhere in their lives: "For example, many people have experienced the increase of quality time in their everyday lives when starting to use some automated tools or domestic robots. In the workplace robots can be given jobs that are dangerous or bad for human health" (T10). In the weaknesses category, the common theme is that people do not have enough knowledge about robotics and AI and, therefore, need to be provided with specialized training courses: "because fresh discoveries have been left to professionals to make, it will take years before they become conveniently available to the wider public. /-I reliability was a constant bottleneck, requiring a professional to be a key player in the solutions, or at least to be constantly present. There were and are so many technical problems that a pedagogue or philologist could be easily drowned in these when acting on their own" (T13). In the opportunities category, the prevalent topic is how AI-enhanced robotics can help to reshape society in unprecedented ways, change how we work, and interact with each other: "we will be surrounded soon by different versions of intelligent systems that will assist us in every task; some of them will resemble our present ideas of what robots are, but some others will be radically different. This situation will necessarily require deep changes, both in society and in the robotics arena" (T2). This is something that can be seen as an advantage but also as a disadvantage as, in the threats category, we also see how people are afraid of the changes that are introduced by robotics with/and AI: "This rapid increase in the number of robots causes some inconvenience and hesitation when considering people's daily income or the future of interpersonal relationships" (T16). Perhaps the most surprising issue is that, with a few exceptions, the participants-higher education teachers and their students-only scarcely described how robotics with AI could impact teaching and learning in higher education. In a way, this suggests that the participants have not really succeeded in associating the technologies with their everyday routines, indicating a need for training courses that would fill this gap.

\subsection{Perceptions of University Teachers, Related to Emerging Technologies}

Our second research question was "What are the perceptions of university teachers related to emerging technologies in general?" Three common themes appeared from empirical material reflecting university teachers' perceptions on three levels: (a) on what and how ETs have been experienced; (b) how emergent technology might be used in light of beliefs and hope; and (c) what might using ETs mean as a future perspective. The main results from the 
thematic analysis are presented below, focusing mainly on three common themes which arise from the empirical material with the variations of subthemes: (a) expectations for use of ETs in general (subthemes: issues, aspects that need to be taken into consideration and future perspectives); (b) opportunities for use of ETs (subthemes: life and society, access and equality in education, university and schools, family, learning and learning support, role of educational robots); and (c) the future use of ETs (Figure 3). Those three common themes formed the common meanings of perceptions of university teachers related to ETs.

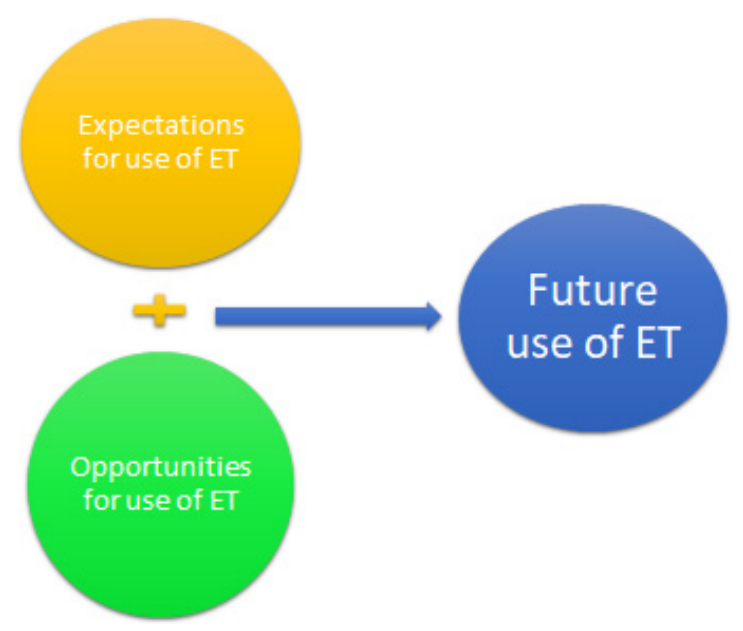

Figure 3. Common themes from thematic analyses.

\subsubsection{Theme 1: Expectation for Use of Emerging Technologies}

For university teachers, the use of ETs is related to relatively common expectations that refer to next subthemes, issues, aspects that need to be taken into consideration, and future perspectives:

- Issues: "There are several issues related to ETs and robots in education: difficulties for adapting robots to teaching curricula and vice versa; lack of expertise of present teachers in robotics and the ways to take advantage of them; lack of clear methodologies and guidelines regarding the systematic application of robotics ..." (T1).

- Aspects that need to be taken into consideration: "There are aspects that need to be taken into consideration while this process takes place. The main one is probably that it is essential to improve the level of acceptance of robots within society" (T1).

- Future perspectives: "Future perspectives related to robots concerns learning, teaching, interpersonal communication and requires rethinking and research based on the specifics of each subject and interdisciplinary integration" (T6).

\subsubsection{Theme 2: Opportunities for Using Emerging Technologies}

From the analysis, it appeared that the area opportunities for using ETs in higher education has more variation than the first theme and referred to the following subthemes: life and society, access and equality in education, university and schools, family, learning, learning support, and role of educational robots:

- $\quad$ Life and society: "In some ways we are already seamlessly becoming the robot's co-travelers. They have integrated so profoundly into our society, our way of life, that removing them from all of it would be nearly impossible" (T2).

- Equality in education: "What is certain is that the use of robotic devices will ensure better accessibility in education in the broadest sense, thus contributing to the creation of equal opportunities and the development of an inclusive society" (T5).

- Educational robots and learning: "The widespread use of educational robots or robotized toys will facilitate the new generations to become soon acquainted with robots. This intimacy with robots will necessarily sip into their families. Therefore, the number of people that will see robots as new useful devices will keep growing steadily... " (T1). "Augmented reality opens 
up unprecedented opportunities to experience objects and phenomena that are traditionally too far away or too tiny, it opens a new page in learning for learners with and without any special needs" (T5).

- Learning support, and the role of educational robots: "The first role of educational robots is to raise awareness on the backstage of technology" (T14). "A robot, programmed to support learning, does not get tired or lose hope, does not express negative emotions, does not laugh at a pronunciation or grammar error, but notices successes, gives encouraging comments, discreetly points out mistakes or can support learners, especially if the learner needs more time to practice. The robot finds time for this and adjusts the content and speech tempo and speed to the learner accordingly. The robot allows us to play through a communication situation in a safe environment and can help provide more objective feedback than the student would be able to do" (T6). "Many other disciplines may benefit from robots if we see them as tools instead of end products. From art to healthcare, robots may solve numerous problems if we fit them into a systemic approach" (T14).

\subsubsection{Theme 3: Future Use of Emerging Technologies}

The third main common theme, the future use of emerging technology, appeared with variations of sub-themes (life and robots, use of robots, future with the robots, ethical and safety aspects about robot use, implication of ET in future education), and allowed us to construct a collective story about the future. Based on the dialogical approach introduced by [48], we constructed this story, using direct quotes from empirical material as empirical illustrations and basis for the story. To make this collective story coherent, we relied upon the structure of the text [51] (p. 438).

\subsubsection{Collective Story of the Future}

Robots are fast becoming a common phenomenon in everyday human life. When we look at human life from a broader perspective, we can see robots being implemented into more and more spheres of life. If a person has always thought about himself and other significant humans in regards to all the different spheres of their life, then now these significant others can also originate from non-biological lifeforms.

In the future, the use of robots in educational activities will be even more of an application to develop social relationships and support teachers in language teaching. In the future, different technologies will be integrated and language learning robots will be able to process learning objectives. There are also many possibilities, different in purpose and combination, such as workshops, simulations, simulation experiments, discovery observations. I cannot imagine everything yet.

Would it be possible to forecast what the future of robots could be like, departing from their past evolution? Very possibly yes; new developments are being produced constantly in basic disciplines, such as AI, computer vision, speech, emotions or gesture recognition, mechatronics. We will soon be surrounded by different versions of intelligent systems that will assist us in every task; some of them will resemble our present ideas of what robots are, but some others will be radically different. This situation will necessarily require deep changes, both in society and in the robotics arena (again, in the broadest sense of the term robotics).

To do this, it is necessary to arouse interest in robotics already in kindergarten. It seems safe to ensure that, in the future, we will be surrounded by robots or similar machines or systems which will help us perform all sorts of tasks; this deployment will be easily accepted by society. As with any kind of previously conceived machine, there will be a learning period after which these systems will become most effective for each user. It is real hope that, in the next decade, robotics tools will become everyday tools in kindergartens and schools, as today every teacher has a computer.

It seems safe to believe that the following years will witness a dramatic influence of robots in our lives. In one way or another, many people will have to familiarize themselves with robot-assisted or robot-oriented jobs. Consequently, it is important that present day 
education takes this belief into consideration, preparing future citizens to be able to achieve maximum yield from robots.

In any case, like with other aspects of technology, ethical and safety aspects about robot use (again, in a wide sense) will have to be taken into consideration. However, in a broader context, the development and use of robots has more implications than just diversifying learning and supporting learners and their learning. With new technology and the developments that come with it, there is a need to constantly learn and create new things. It is clear that we will need to learn how to take advantage of these devices, just like with any other man-made tool. In addition, that implies at least a basic familiarity and understanding of the technology, its capabilities, and its shortcomings. This is one of the goals the Education system should pursue.

We hope that this story might provoke critical discussions and some new changes or even ideas in the teaching and learning practice at the universities.

In finalizing this subsection, it is important to add that our findings demonstrate that university teachers have positive intentions, attitudes, and common perceptions due to their previous experience related to using ETs which is similar to findings from previous studies [52].

\section{Discussion}

The aim of the paper was to gain a deep understanding of the perceptions and points of view of university teachers and their students on ETs in their future life, as well as their impact on society in general and particularly on their teaching practices. The focus in the empirical analysis was on the strengths, weaknesses, opportunities, and threats of the proliferation of ETs, and on the perceptions of university teachers related to ETs. Teachers' perceptions related to ETs appeared on three levels: on what and how ETs have been experienced, how emergent technology might be used in light of beliefs, and hope and what might using ETs mean as a future perspective. The results of our research provide supporting evidence that previous experience related to ETs can support implementations and transformations in teaching and learning practices at the university.

One of the inherent characteristics of ETs is their novelty-in theory they have many promising features, but in practice it is difficult to estimate their true future success. In addition, ETs lack a well-developed user community or knowledge base about the best practices, as these are going to evolve concurrently with the spread of ETs. For these reasons, implementation of ETs may prove to be challenging.

Our findings showed that the teachers' perceptions related to ETs were based on general understanding of these technologies without going into the specifics of their teaching disciplines. In addition, the participants either had optimistic and positive expectations towards ETs or were accepting them as a part of the inevitable progress and teaching practice. It is possible that this is due to associating novel technologies with people's well-being $[53,54]$. The positive outlook on emerging technologies can also be caused by the already established correlation between having a previous experience with increasing knowledge about a technology and having more positive attitudes towards the technology [26,31,32]. This correlation has also been demonstrated in our earlier paper [55] that observed the change in attitudes of 16 higher education students after a 2-day workshop about AI-enhanced robots.

Based on findings it is evident that university teachers perceived the ETs as promising possibilities and were ready to implement them, possibly if ready-made solutions were available - while the discussion about the negative effects of ETs was insignificant. However, the scarce presence of negative aspects of ETs in participants' contributions could not really indicate that implementing ETs has no problems. According to [56], persons with inadequate knowledge about a technology are more likely to be influenced by so-called optimistic bias, an attitude that fades as the persons become more knowledgeable about the technology. The scarce presence of details in participants' visions regarding the integration of technologies with their disciplines leads us to suggest that the participants might 
have insufficient knowledge about the relationship between the practical realities of the technology and their discipline-explaining the optimistic bias. The teachers' difficulties of connecting technology with teaching practices have also been noted earlier in the literature (e.g., [57,58]). Addressing this deficiency requires a few approaches to be considered when introducing ETs to higher education teaching practices. Based on the findings, it can be concluded that a combination of several interventions and developments is needed.

First, the principal responsibility for the successful and sustainable integration of ETs lies on initiators of the change-researchers, university teachers, policymakers, administrators, and other stakeholders. The integration should be planned as a thorough process with all its stages and factors covered to maximum detail in order to become sustained in teaching practices (see [7]). A particular focus should be on providing teachers with relevant training courses about the technology in question and ways of connecting it with the pedagogical goals. Secondly, as many teachers as possible should be involved in order to shape the best teaching practices that would work in "average classrooms operated by and for average students and teachers" [59]. Large participation could also ensure forming a functional support community, and using the co-creation approach can help to develop efficient teaching and learning artefacts while improving the adoption of ETs [60].

Considering that people trust emerging technologies more than humans in some domains today [28], even though these technologies have been around for a little time only, it is crucial for future developments that people are offered thorough knowledge about the possibilities and limitations of the technologies that lead their lives. Higher education, and education in general, is particularly responsible for this to happen: "we will need to learn how to take advantage of ET just like with any other man-made tool. And that implies at least a basic familiarity and understanding of the technology, its capabilities, and its shortcomings. This is one of the goals the education system should pursue" (T1).

\section{Limitations and Future Directions}

In this paper, we examined the written and recorded visions from 18 university teachers and students who had previously taken part in a specialized program about AI-enhanced robotics. The quality of the collected data could be improved by increasing the sample size, including persons without previous training about this area (but also, as a control group, persons with a wider knowledge base about this area), and involving a wider variety of ETs. In addition, semi-structured interviews could be more suitable for collecting more detailed empirical data. Future research in this field could focus on the teachers' understanding about the connections between ETs and their field of teaching. It is possible that such studies should include a pre-study training so that university teachers would be able to better evaluate the ETs in the context of their teaching practices.

Author Contributions: Conceptualization: J.L. and L.J.; Methodology: J.L. and L.J.; Validation: T.Õ. and L.P.; Formal Analysis: J.L. and L.J.; Investigation: J.L.; Resources: J.L.; Data Curation: J.L.; Writing-Original Draft Preparation: J.L., L.J., T.Õ., J.S.M.L.; Writing: J.L., L.J., L.P., T.Õ.; Visualization: J.L. and L.J.; Supervision: J.L., I.G.; Project Administration: J.L.; Funding Acquisition; T.Õ. All authors have read and agreed to the published version of the manuscript.

Funding: The article processing charges were funded by the School of Educational Sciences, Tallinn University.

Institutional Review Board Statement: Not applicable.

Informed Consent Statement: Not applicable.

Data Availability Statement: The data that was used in this study is available at: https://drive. google.com/drive/folders/1qA7g6TjwFEXq6t0iP-Zv7pP7TC0LSnhE? usp=sharing (accessed on 6 September 2021).

Conflicts of Interest: The authors declare no conflict of interest. 


\section{References}

1. Adner, R.; Levinthal, D.A. The Emergence of Emerging Technologies. Calif. Manag. Rev. 2002, 45, 50-66. [CrossRef]

2. Rotolo, D.; Hicks, D.; Martin, B. What is an emerging technology? Res. Policy 2015, 44, 1827-1843. [CrossRef]

3. Schumpeter, J.A. The Theory of Economic Development: An Enquiry into Profits, Capital, Credit, Interest and the Business Cycle; Oxford University Press: London, UK, 1934.

4. $\quad$ Rogers, E.M. Diffusion of Innovations, 5th ed.; Free Press: New York, NY, USA, 2003.

5. Davis, F.D. Technology Acceptance Model for Empirically Testing New End-User Information Systems: Theory and Results; Massachusetts Institute of Technology: Cambridge, MA, USA, 1985.

6. Cozzens, S.; Gatchair, S.; Kang, J.; Kim, K.-S.; Lee, H.J.; Ordóñez, G.; Porter, A. Emerging technologies: Quantitative identification and measurement. Technol. Anal. Strateg. Manag. 2010, 22, 361-376. [CrossRef]

7. Leoste, J.; Heidmets, M.; Ley, T.; Stepanova, J. Classroom Innovation Becoming Sustainable: A Study of Technological Innovation Adoption by Estonian Primary School Teachers. IxDA Interact. Des. Archit. 2021, 42, 144-166.

8. Oliveira, A.; Behnagh, R.F.; Ni, L.; Mohsinah, A.A.; Burgess, K.J.; Guo, L. Emerging technologies as pedagogical tools for teaching and learning science: A literature review. Hum. Behav. Emerg. Technol. 2019, 1, 149-160. [CrossRef]

9. Elliott, S.W. Computers and the Future of Skill Demand; OECD Publishing: Paris, France, 2017. [CrossRef]

10. OECD. The Future of Education and Skills. Education 2030; OECD: Paris, France, 2018.

11. Verbeek, P.P. Don Ihde: The technological lifeworld. In American Philosophy of Technology: The Empirical Turn; Achterhuis, H., Ed.; Indiana University Press: Bloomington, IN, USA, 2001; pp. 119-146.

12. Crieghton, J. Today, Michio Kaku Described What Life Will Look Like in Twenty Years. Futurism. 2018. Available online: https: / / futurism.com/michio-kaku-life-20-years-future/ (accessed on 25 July 2021).

13. Joint Information Systems Committee. Horizons Report on Emerging Technologies and Education; JISC: Bristol, UK, 2019.

14. Visvizi, A.; Lytras, M.D.; Sarirete, A. Emerging Technologies and Higher Education: Management and Administration in Focus. In Management and Administration of Higher Education Institutions at Times of Change; Visvizi, A., Lytras, M.D., Sarirete, A., Eds.; Emerald Publishing Ltd.: Bingley, UK, 2019; pp. 1-11. [CrossRef]

15. Mavroudi, A.; Papadakis, S. A Case Study on How Greek Teachers Make Use of Big Data Analytics in K-12 Education. In Emerging Technologies for Education. SETE 2019; Popescu, E., Hao, T., Hsu, T.C., Xie, H., Temperini, M., Chen, W., Eds.; Springer: Cham, Switzerland, 2020. [CrossRef]

16. Reyes, J.A. The skinny on big data in education: Learning analytics simplified. TechTrends 2015, 59, 75-80. [CrossRef]

17. Mystakidis, S.; Christopoulos, A.; Pellas, N. A systematic mapping review of augmented reality applications to support STEM learning in higher education. Educ. Inf. Technol. 2021. [CrossRef]

18. Pellas, N.; Mystakidis, S.; Kazanidis, I. Immersive Virtual Reality in K-12 and Higher Education: A systematic review of the last decade scientific literature. Virtual Real. 2021, 25, 835-861. [CrossRef]

19. Mystakidis, S.; Berki, E.; Valtanen, J.-P. Deep and Meaningful E-Learning with Social Virtual Reality Environments in Higher Education: A Systematic Literature Review. Appl. Sci. 2021, 11, 2412. [CrossRef]

20. Spolaôr, N.; Benitti, F.B.V. Robotics applications grounded in learning theories on tertiary education: A systematic review. Comput. Educ. 2017, 112, 97-107. [CrossRef]

21. Conde, M.Á.; Rodríguez-Sedano, F.J.; Fernández-Llamas, C.; Gonçalves, J.; Lima, J.; García-Peñalvo, F.J. Fostering STEAM through challenge-based learning, robotics, and physical devices: A systematic mapping literature review. Comput. Appl. Eng. Educ. 2021, 29, 46-65. [CrossRef]

22. Cook, V.S.; Gregory, R.L. Emerging technologies: It's not what you say-It's what they do. Online Learn. 2018, 22, 121-130. [CrossRef]

23. Grimus, M. Emerging Technologies: Impacting Learning, Pedagogy and Curriculum Development. In Emerging Technologies and Pedagogies in the Curriculum. Bridging Human and Machine: Future Education with Intelligence; Yu, S., Ally, M., Tsinakos, A., Eds.; Springer: Singapore, 2020. [CrossRef]

24. Niederhauser, D.S.; Howard, S.K.; Voogt, J.; Agyei, D.D.; Laferriere, T.; Tondeur, J.; Cox, M.J. Sustainability and Scalability in Educational Technology. Technol. Knowl. Learn. 2018, 23, 507-523. [CrossRef]

25. Varghese, N.V.; Mandal, S. Teaching-Learning and New Technologies in Higher Education: An Introduction. In Teaching Learning and New Technologies in Higher Education; Varghese, N.V., Mandal, S., Eds.; Springer: Singapore, 2020. [CrossRef]

26. EuRobotics AISBL. Robotics 2020-Strategic Research Agenda for Robotics in Europe. Years 2014-2020; SPARC: Brussels, Belgium, 2015.

27. Clarke, R. Principles and business processes for responsible AI. Comput. Law Secur. Rev. 2019, 35, 410-422. [CrossRef]

28. Oracle; Savanta. Money and Machines: 2021 Global Study; Oracle Corporation: Austin, TX, USA, 2021; Available online: https: //www.oracle.com/a/ocom/docs/applications/erp/money-and-machines-report-2021.pdf (accessed on 25 July 2021).

29. Wisskirchen, G.; Biacabe, B.T.; Bormann, U.; Muntz, A.; Niehaus, G.; Soler, G.J.; von Brauchitsch, B. Artificial Intelligence and Robotics and Their Impact on the Workplace; IBA Global Employment Institute: London, UK, 2017.

30. United Nations. World Economic and Social Survey 2018; United Nations: New York, NY, USA, 2018.

31. Leite, I.; Martinho, C.; Paiva, A. Social robots for long-term interaction: A survey. Int. J. Soc. Robot. 2013, 5, 291-308. [CrossRef]

32. Turja, T.; Van Aerschot, L.; Särkikoski, T. Finnish healthcare professionals' attitudes towards robots: Reflections on a population sample. Nurs. Open 2018, 5, 300-309. [CrossRef] 
33. Hennick, C. Leaps, Bounds, and Backflips. Boston Dynamics, 2017. Available online: http://blog.bostondynamics.com/atlasleaps-bounds-and-backflips (accessed on 25 August 2021).

34. Venkatraman, N. IT-enabled business transformation: From automation to business scope redefinition. Sloan Manag. 1994, 35, 73-87.

35. Rogers, P.L. Barriers to Adopting Emerging Technologies in Education. J. Educ. Comput. Res. 2000, 22, 455-472. [CrossRef]

36. Davenport, T.H. Process management for knowledge work. In Handbook on Business Process Management 1, 2nd ed.; vom Brocke, J., Rosemann, M., Eds.; Springer: Berlin/Heidelberg, Germany, 2015; pp. 17-35. [CrossRef]

37. Milles, M.; Huberman, A.M.; Saldana, J. Qualitative Data Analysis. A Methods Sourcebook, 4th ed.; SAGE Publications Inc.: Thousand Oaks, CA, USA, 2019.

38. Jeffreys, B. PISA Rankings-Why Estonian Pupils Shine in Global Tests. BBCS News. 2019. Available online: https://www.bbc. com/news/education-50590581 (accessed on 25 August 2021).

39. Haridusvaldkonna Arengukava 2021-2035. Haridus-ja Teadusministeerium. Tallinn. 2020. Available online: https://www.hm. ee/sites/default/files/eesti_haridusvaldkonna_arengukava_2035_seisuga_2020.03.27.pdf (accessed on 25 July 2021).

40. Li, L.Y. Exploring the Use of Focused Freewriting in Developing Academic Writing. J. Univ. Teach. Learn. Pract. 2007, 4, 41-53.

41. Finlay, L. Debating phenomenological research methods. Phenomenol. Pract. 2009, 3, 6-25. [CrossRef]

42. Braun, V.; Clarke, V. Using thematic analysis in psychology. Qual. Res. Psychol. 2006, 3, 77-101. [CrossRef]

43. Marton, F. Phenomenography-A research approach investigating different understandings of reality. J. Thought 1986, 21, 28-49.

44. Benjamin, S. When Plan A Falls through: Using a Collective Story Methodology to Construct a Narrative. In Proceedings of the TTRA International Conference, Vail, CO, USA, 15-17 June 2016.

45. Hems, M.M.; Nixon, J. Exploring SWOT analysis-Where are we? A review of academic research from the last decade. J. Strateg. Manag. 2010, 3, 215-251. [CrossRef]

46. Gürel, M.; Tat, M. SWOT analysis: A theoretical review. J. Int. Soc. Res. 2017, 10, 994-1006. [CrossRef]

47. Saldana, J. The Coding Manual for Qualitative Researchers; SAGE Publications Inc.: London, UK, 2009.

48. Frank, A.W. Letting Stories Breathe: A Socio-Narratology; University of Chicago Press: Chicago, IL, USA, 2010.

49. Saltmarshe, E. Telling the Difference: Using Story to Change Systems; Calouste Gulbenkian Foundation (UK Branch): London, UK, 2018.

50. Nowell, L.; Norris, J.; White, D.; Moules, N. Thematic Analysis: Striving to Meet the Trustworthiness Criteria. Int. J. Qual. Methods 2017, 16, 1-13. [CrossRef]

51. Jõgi, L.; Karu, K. Nordic-Baltic cooperation in adult education: A collective story of Estonian adult educators. Int. Rev. Educ. 2018, 64, 421-441. [CrossRef]

52. Scherera, R.; Teo, T. Unpacking teachers' intentions to integrate technology: A meta-analysis. Educ. Res. Rev. 2019, 27, 90-109. [CrossRef]

53. Riva, G. What is positive technology and its impacts on cyberpsychology. Stud. Health Technol. Inf. 2012, 181, 37-41.

54. Grossi, G.; Lanzarotti, R.; Napoletano, P.; Noceti, N.; Odone, F. Positive technology for elderly well-being: A review. Pattern Recognit. Lett. 2020, 137, 61-70. [CrossRef]

55. Leoste, J.; Viik, T.; San Martín López, J.; Kangur, M.; Vunder, V.; Mollard, Y.; Õun, T.; Tammo, H.; Paekivi, K. Robots as my future colleagues: Changing attitudes towards collaborative robots by means of experience-based workshops. In Smart Innovation, Systems and Technologies, Proceedings of the 6th Conference on Smart Learning Ecosystems and Regional Development (SLERD 2021), Online, 24-25 June 2021; Mealha, O., Dascalu, M., Di Mascio, T., Eds.; Springer: Singapore, 2021.

56. Hewitt, B.; White, G.L. Optimistic Bias and Exposure Affect Security Incidents on Home Computer. J. Comput. Inf. Syst. 2020, 1-11. [CrossRef]

57. Naidoo, J. Transforming the Classroom Context. Mathematics Teachers' Experiences of the Use of Technology-Enabled Pedagogy for Embracing the Fourth Industrial Revolution. In Teaching and Learning in the 21st Century. Embracing the Fourth Industrial Revolution; Brill: Leiden, The Netherlands; Boston, MA, USA, 2021.

58. Angeli, C.; Valanides, N. Epistemological and methodological issues for the conceptualization, development, and assessment of ICT-TPCK: Advances in technological pedagogical content knowledge (TPCK). Comput. Educ. 2009, 52, 154-168. [CrossRef]

59. Brown, A.L. Design experiments: Theoretical and methodological challenges in creating complex interventions in classroom settings. J. Learn. Sci. 1992, 2, 141-178. [CrossRef]

60. Rodríguez-Triana, M.J.; Prieto, L.P.; Ley, T.; de Jong, T.; Gillet, D. Social practices in teacher knowledge creation and innovation adoption: A large-scale study in an online instructional design community for inquiry learning. Int. J. Comput. Supported Collab. Learn. 2020, 15, 445-467. [CrossRef] 